\title{
Presence of depressive symptoms in patients with a first episode of Acute Coronary Syndrome ${ }^{1}$
}

\author{
Carina Aparecida Marosti Dessotte ${ }^{2}$ \\ Fernanda Souza e Silva ${ }^{3}$ \\ Fabiana Bolela ${ }^{4}$ \\ Lidia Aparecida Rossi ${ }^{5}$ \\ Rosana Aparecida Spadoti Dantas ${ }^{6}$
}

\begin{abstract}
Aim: to compare possible differences regarding the presence of depressive symptoms according to the clinical diagnosis of Acute Coronary Syndrome, gender and age, one week before the first cardiac event. Method: cross-sectional, descriptive and exploratory study, which used the Beck Depression Inventory. The sample consisted of 253 patients. Results: it was found that patients with a clinical diagnosis of unstable angina, female and under 60 years of age reported the presence of depressive symptoms more frequently. Conclusion: a high percentage of patients presented depressive symptoms at the time of hospitalization for the first episode of Acute Coronary Syndrome, and this prevalence was significantly higher among women, under 60 years of age, with unstable angina. These results should provide support for the care in the hospitalization, discharge and planning of the rehabilitation of these patients, as it is known that depression impairs the control of coronary disease.
\end{abstract}

Descriptors: Acute Coronary Syndrome; Depression; Coronary Disease.

\footnotetext{
${ }^{1}$ Paper extracted from doctoral dissertation "Avaliação da qualidade de vida relacionada à saúde de pacientes infartados e com angina" presented to Escola de Enfermagem de Ribeirão Preto, Universidade de São Paulo, WHO Collaborating Centre for Nursing Research Development, Ribeirão Preto, SP, Brazil.

2 PhD, Professor, Escola de Enfermagem de Ribeirão Preto, Universidade de São Paulo, WHO Collaborating Centre for Nursing Research Development, Ribeirão Preto, SP, Brazil.

${ }^{3}$ Doctoral student, Programa Interunidades de Pós-graduação em Enfermagem, Escola de Enfermagem, Universidade de São Paulo, São Paulo, SP, Brasil and Escola de Enfermagem de Ribeirão Preto, Universidade de São Paulo, WHO Collaborating Centre for Nursing Research Development, Ribeirão Preto, SP, Brazil.

${ }^{4}$ Doctoral student, Escola de Enfermagem de Ribeirão Preto, Universidade de São Paulo, WHO Collaborating Centre for Nursing Research Development, SP, Brazil. RN, Hospital Estadual de Ribeirão Preto, Ribeirão Preto, SP, Brazil.

${ }^{5} \mathrm{PhD}$, Full Professor, Escola de Enfermagem de Ribeirão Preto, Universidade de São Paulo, WHO Collaborating Centre for Nursing Research Development, SP, Brazil.

${ }^{6} \mathrm{PhD}$, Associate Professor, Escola de Enfermagem de Ribeirão Preto, Universidade de São Paulo, WHO Collaborating Centre for Nursing Research Development, SP, Brazil.
} 


\section{Introduction}

The World Health Organization has provided consistent estimates of causes of death by sex and age, for countries and regions, from systematic reviews of observational evidence. The most recent data show that the cardiovascular diseases (CVD), particularly Acute Myocardial Infarction (AMI), represent the major cause of mortality and disability in both sexes, both in Brazil and worldwide. Their growth is rapid in developing countries, and they represent one of the more relevant public health issues today(1). The Acute Coronary Syndromes (ACS) include conditions such as AMI and unstable angina (UA) and are caused by the rupture of atheromatous plaques with either total or partial occlusion of the coronary bed ${ }^{(2-3)}$.

Specific emotions such as anxiety, nervousness and depression have emerged as potential risk factors for the onset of AMI and UA ${ }^{(4-5)}$. These emotions can influence cardiovascular health in various ways, for example, in the excessive activation of the sympathetic nervous system causing an increase in its operation, leading to tachycardia and arterial hypertension, predisposing factors found in cardiac events. Currently, there is evidence that depression affects about $20 \%$ of patients with coronary artery diseases ${ }^{(6-7)}$. For this reason it is considered important to know the emotional state of individuals in the week preceding hospitalization as a result of the first episode of the ACS.

Depression is one of the most common psychiatric pathologies. It is found in all cultures and afflicts a considerable portion of the population, regardless of gender, age or ethnicity, with it constituting the factor of greatest personal, social and functional injury today ${ }^{(8)}$. Furthermore it is considered one of the six leading causes of disability during life, and is projected to be the main cause by $2030^{(9)}$. The interest in the association between depression and the cardiac diseases has been highlighted due to the increased prevalence and morbimortality of these diseases, with the consequent increment in the cost and length of evolution of the disease, length of time away from work, as well as increasing the demand for procedures and complementary examinations, generating a high cost for the Brazilian National Health System (SUS) and it complementary service ${ }^{(10)}$.

After a literature review a small number of studies were found involving depression in patients with $\operatorname{ACS}^{(4,11-13)}$, and no studies were found that had the aim of evaluating depressive symptoms perceived by the patients considering the week prior to hospitalization due the first episode of ACS.

\section{Aims}

Given the above, this study was developed with the aim of investigating possible differences regarding the presence of depressive symptoms according to the clinical diagnosis of ACS (AMI and UA), gender and age, one week prior to hospitalization due to the first cardiac event.

\section{Methods}

This is a descriptive, exploratory, cross sectional study, developed in the coronary care units and cardiology wards of two hospitals located in the state of São Paulo. For the sample size calculation, the following values, used in multiple linear regression models, were considered: maximum number of predictors equal to six, effect size equal to 0.10 , significance level $(\alpha)$ equal to 0.05 and test power $(1-\beta)$ equal to 0.95 . This produced an estimated number of 216 subjects. These values were entered into software available from the website: http://www.danielsoper.com/statcalc/calc01. aspx.

Considering the existence of two groups of subjects, according to the clinical diagnosis of ACS (AMI and UA) and a homogeneous distribution of these diagnoses among the 216 subjects, a minimum number of 108 participants in each group was sought. Being a sample that was consecutively composed, without the control of the diagnoses to be found in the course of the study, 142 patients with AMI and 111 with UA were interviewed, totaling 253 subjects. Therefore, the study sample consisted of patients with coronary heart disease, aged over 21 years, hospitalized in the previously mentioned hospitals, due to the first episode of UA or AMI. Patients were selected considering the following inclusion criteria: to be in a clinical condition (physical and psychological) to respond to the questionnaires and instruments. Data collection was carried out from May 2006 to July 2009. The project was approved by the Research Ethics Committee of the hospitals. The study participants were duly informed about the study, both verbally and in writing, and the Terms of Free Prior Informed Consent were signed by the patients and researchers.

All the data were collected through individual interviews with the participants during their hospitalization. The data collection instrument considered socio-demographic (gender, marital status, 
the performance of remunerated activities and date of birth) and clinical variables (ACS diagnosis during hospitalization and presence of previous treatments for other CVDs). Subsequently, the age of the participants was calculated. The use of psychotropic drugs during the hospitalization was investigated as this could compromise the evaluation of the participants regarding their perceptions of the depressive symptoms.

The presence of depressive symptoms was evaluated using the adapted Portuguese version ${ }^{(15)}$ of the "Beck Depression Inventory" (BDI) instrument ${ }^{(14)}$. This is an inventory composed of 21 categories of symptoms and attitudes, where each category describes a specific behavioral manifestation of depression and consists of a series of four to five self-assessment statements. The 21 categories are: sadness, pessimism, past failure, loss of pleasure, guilty feelings, punishment feelings, selfdislike, self-criticalness, suicidal thoughts or wishes, crying, agitation, loss of interest, indecisiveness, worthlessness, loss of energy, changes in sleeping pattern, irritability, changes in appetite, concentration difficulty, tiredness or fatigue and loss of interest in sex. Numeric values of zero to three are assigned to these statements to classify the degree of depression. After a literature review, it was observed that there are several proposals of different cutoff points to distinguish the degrees of depression using the BDI. In the present study, the following evaluation was used(16), considering an absence of any previous diagnosis of depression: scores between zero and nine - no depression, scores between 10 and 16 - "dysphoria" (general indisposition, permanent malaise) scores of 17 to 20 - mild depressive state, scores of 21 to 30 - moderate depression, and finally, scores above 30 reflecting severe depression. The Cronbach's alpha coefficient value for the BDI instrument in this study was 0.89 , indicating good internal consistency ${ }^{(17)}$.

For the data analysis, descriptive analyses of simple frequency were performed for the nominal or categorical variables, and analyses of central tendency (mean and median) and dispersion (standard deviation) for the continuous variables. To achieve the study aims, the following statistical tests were employed: test of association (chi-square) to evaluate possible associations between the presence of depressive symptoms and the clinical diagnosis of ACS (AMI or UA), gender and age group, and the Student's t-test for independent samples to compare the means and medians of the depression measurements (BDI) according to the three variables of interest. The significance level adopted was 0.05 .

\section{Results}

Of the 253 patients interviewed, 142 (56\%) were hospitalized with their first episode of AMI and 111 (44\%) with the first episode of UA. The sociodemographic characterization of the subjects is shown in Table 1. Values are presented in descending order according to the predominant group for each of the variables.

Table 1 - Sociodemographic characterization of the subjects by gender, marital status and performance of remunerated activities, according to the clinical diagnosis of ACS. Ribeirão Preto, SP, Brazil, 2006-2009

\begin{tabular}{|c|c|c|}
\hline \multirow{2}{*}{ Variable } & AMI $(n=142)$ & UA $(n=111)$ \\
\hline & n (\%) & n (\%) \\
\hline \multicolumn{3}{|l|}{ Gender } \\
\hline Male & $106(74.6)$ & $69(62.2)$ \\
\hline Female & $36(25.4)$ & $42(37.8)$ \\
\hline \multicolumn{3}{|l|}{ Marital status } \\
\hline Married/consensual union & $95(66.9)$ & $81(71)$ \\
\hline Single & $18(12.7)$ & $07(6.3)$ \\
\hline Separated & $16(11.3)$ & $10(9)$ \\
\hline Widowed & $13(9.2)$ & $13(11.7)$ \\
\hline \multicolumn{3}{|c|}{ Performance of remunerated activities } \\
\hline Yes & $92(64.8)$ & $55(49.5)$ \\
\hline
\end{tabular}

Regarding the age variable, the group of patients with a diagnosis of AMI presented a lower mean age compared with the values obtained for the group of patients with $\mathrm{UA}$ : $55.8(\mathrm{SD}=13)$ years and $60.6(\mathrm{SD}=10.5)$ years, respectively. The AMI patients were younger than the patients with UA and this difference was statistically significant $(p=0.01)$. Regarding the association between the presence of previous treatment for CVDs and other clinical manifestation of ACS, statistically significant result were found $(p<0.001)$. It was observed that $70.3 \%$ of the patients in the UA group had already undergone previous treatment for these diseases, however, this percentage was $44.4 \%$ among the AMI patients. The use of psychotropic drugs during the hospitalization was also more frequent among the UA patients $(77 ; 69.4 \%)$ than among the AMI patients $(28 ; 19.7 \%)$, with this association being statistically significant $(p=0.045)$.

To evaluate the possible associations between the presence of depressive symptoms and age group, the sample was grouped by age considering two groups: adults - study subjects aged between 21 and 59 years and elderly - subjects over 60 years. The results regarding the possible associations between the presence of depressive symptoms and clinical manifestation of ACS, gender and age group are shown in Table 2. 
Table 2 - Distribution of the participants according to the classification of the values of the Beck Depression Inventory (BDI) and clinical presentation of ACS, gender and age group. Ribeirão Preto, SP, Brazil, 2006-2009

\begin{tabular}{|c|c|c|c|c|c|c|}
\hline \multirow[t]{2}{*}{ Variable } & $\begin{array}{c}\text { Depression } \\
\text { absent }\end{array}$ & Dysphoria & $\begin{array}{c}\text { Mild } \\
\text { depression }\end{array}$ & $\begin{array}{c}\text { Moderate } \\
\text { depression }\end{array}$ & $\begin{array}{c}\text { Severe } \\
\text { Depression }\end{array}$ & \multirow{2}{*}{$p^{*}$} \\
\hline & n (\%) & n (\%) & n (\%) & n (\%) & n (\%) & \\
\hline \multicolumn{7}{|l|}{ Diagnosis } \\
\hline AMI $(n=142)$ & $92(64.8)$ & $25(17.6)$ & $09(6.3)$ & $12(8.5)$ & $04(2.8)$ & \multirow{2}{*}{0.015} \\
\hline UA $(n=111)$ & $51(45.9)$ & $24(21.6)$ & $11(9.9)$ & $13(11.7)$ & $12(10.8)$ & \\
\hline \multicolumn{7}{|l|}{ Gender } \\
\hline Male $(n=175)$ & $114(65.1)$ & $32(18.3)$ & $09(5.1)$ & $14(8.0)$ & $06(3.4)$ & \multirow{2}{*}{0.000} \\
\hline Female $(n=78)$ & $29(37.2)$ & $17(21.8)$ & $11(14.1)$ & $11(14.1)$ & $10(12.8)$ & \\
\hline \multicolumn{7}{|l|}{ Age group } \\
\hline Adult $(n=142)$ & $74(52.1)$ & $33(23.2)$ & 07 (4.9) & $16(11.3)$ & $12(8.5)$ & \multirow{2}{*}{0.037} \\
\hline Elderly $(n=111)$ & $69(62.2)$ & $16(14.4)$ & $13(11.7)$ & $09(8.1)$ & $04(3.6)$ & \\
\hline
\end{tabular}

$* p$ value from the Chi-square test

It can be observed that in the group of patients with AMI, the percentage of patients classified without depressive symptoms was higher (64.8\%) than among the UA patients (45.9\%). When considering the categories "mild depression, moderate depression and severe depression", $32.4 \%$ of the patients in the group of UA patients were found within these categories compared with $17.6 \%$ of the AMI patients, with this difference being statistically significant $(p=0.015)$. In the study sample, differences were also found in the presence of depressive symptoms between the genders. It can be observed that the majority of the men (65\%) reported no depressive symptoms in the week prior to the first hospitalization due to ACS, while $41 \%$ of the women reported depressive symptoms during the same period $(p=0.000)$. Finally, differences were also found in the presence of depressive symptoms according to the age group. Adult patients reported the presence of depressive symptoms more frequently when compared with the elderly group ( $24.7 \%$ and $23.4 \%$, respectively) $(p=0.037)$.

\section{Discussion}

The characterization of the study participants regarding age is similar to other studies on coronary artery diseases(4,18-21). Concerning the gender of the participants, there was a prevalence of men, which was also found in other studies that addressed individuals with coronary artery diseases ${ }^{(4,18-23)}$. The predominant marital status in the study was being married or living in a consensual union, which was also found to be the most frequent in the literature ${ }^{(4,19-20,24)}$.

Regarding the presence of depression in the week prior to the hospitalization due to the first episode of ACS, a prevalence of $43.5 \%$ was found in this sample, according to the values obtained through the BDI. A total of $19.4 \%$ of the patients were classified with dysphoria, $7.9 \%$ with mild depression, $9.9 \%$ with moderate depression and $6.3 \%$ with severe depression. These results differ from those obtained by other authors ${ }^{(11)}$ who evaluated 135 patients with ACS, although not necessarily the first episode, and found a higher frequency of patients classified as having some degree of depression. The prevalence of depression found by them was $53.3 \%$, with a higher percentage of patients classified with moderate to severe depression: $28.1 \%$ with mild depression, $14.1 \%$ with moderate depression and $11.1 \%$ with severe depression.

The results of the present study also differ from another study, which presented differences ${ }^{(4)}$ regarding the prevalence of depression among patients with ACS, as measured through the BDI. The authors evaluated 345 patients and found a prevalence of depression of $55 \%$. This study also found higher values of prevalence for moderate depression: $33.3 \%$ were classified with mild depression, $14.1 \%$ with moderate depression and $11.1 \%$ with severe depression. It can be said that, according to these results, patients who were interned due to the first episode of the ACS presented a high prevalence of depression and, considering the results obtained by other authors ${ }^{(4,11)}$, it can be inferred that the depression tends to increase with time, demonstrating the importance of its early recognition and treatment.

When analyzing the possible difference in the presence of depressive symptoms between patients with AMI and UA, values were obtained that indicate a higher prevalence among patients with UA. This difference between the groups was statistically significant. No studies were found in the literature that evaluate possible differences in the presence of depressive symptoms between patients with the first AMI and UA, making it 
impossible to compare the data obtained in this study. The higher prevalence of depressive symptoms among the women hospitalized due to ACS, also was found in national(4,11) and in international studies ${ }^{(25)}$, however, it is worth mentioning the these studies included all patients with ACS, independent of whether this was the first episode. In a national study, adult patients hospitalized due to ACS also reported the presence of depressive symptoms more frequently than the elderly patients ${ }^{(4)}$, which corroborates the results found in the present study.

\section{Conclusion}

A high prevalence of depressive symptoms was found among patients who were hospitalized as a result of the first episode of ACS (43.5\%). The patients hospitalized with UA, female and under the age of sixty years more frequently reported the presence of depressive symptoms. It is believed that these results will support the nursing team in the early detection of individuals with coronary artery disease who have more difficulty in rehabilitation, due to their depression reflecting as feelings of inability to change and to maintain behaviors conducive to cardiovascular health, such as: adopting a healthy diet, practicing physical exercise, medical and multidisciplinary monitoring, and the cessation of smoking and alcohol consumption.

As a limitation of the present study, the absence of other national or international studies, which investigate the presence of depressive symptoms at the time of the first cardiac event, complicated the comparison of our results. The development of an effective monitoring strategy for these patients is suggested as further research, making it possible to support pharmacological and non- pharmacological adherence both with regard to the control and treatment of the depression and the cardiac disease itself, in order to enable the achievement of a better quality of life for these people.

\section{References}

1. Mattos LA, Lemos-Neto PA, Rassi AJ, Marin-Neto JA, Sousa AGMR. Diretrizes da Sociedade Brasileira de Cardiologia - Intervenção Coronária Percutânea e Métodos Adjuntos Diagnósticos em Cardiologia Intervencionista (II Edição - 2008). Arq Bras Cardiol. [periódico na Internet]. 2008 [acesso 6 jun 2012]; 91(4 Supl 1):1-58. Disponível em: http://publicacoes. cardiol.br/consenso/2008/diretriz_INTERVENCAO_ PERCUTANEA-9106.pdf.
2. Kushner FG, Hand M, Smith SC, King SB, Anderson $\mathrm{JL}$, Antman EM, et al. ACC/AHA guidelines for the management of patients with ST-elevation myocardial infarction (updating the 2004 guideline and 2007 focused update) and ACC/AHA/SCAI guidelines on percutaneous coronary intervention (updating the 2005 guideline and 2007 focused update) a report of the American College of Cardiology Foundation/American Heart Association Task Force on Practice Guidelines. J Am Coll Cardiol. [periódico na Internet]. 2009 [acesso 6 jun 2012]; 54(23):2205-41. Disponível em: http://guideline.gov/ content. aspx?id=12192.

3. Finn AV, Nakano M, Narula J, Kolodgie FD, Virmani R. Arteriosclerosis, Thrombosis, and Vascular Biology. Arterioscler Thromb Vasc Biol. 2010; 30:1282-92.

4. Perez GH, Nicolau JC, Romano BW, Laranjeira R. Depression and Acute Coronary Syndromes: genderrelated differences. Arq Bras Cardiol [periódico na Internet]. 2005 [acesso 6 jun 2012]; 85(5):31926. Disponível em: http://www.scielo.br/pdf/abc/ v85n5/26925.pdf.

5. Vogelzangs N, Seldenrijk A, Beekman ATF, Hout HPJV, Jonge P, Penninx BWJH. Cardiovascular disease in Pearson with depressive and anxiety disorders. ] Affective Disorders. [periódico na Internet]. 2010 [acesso 19 jun 2012]; 125(1-3):241-8. Disponível em: http://www.sciencedirect.com/science/article/pii/ S0165032710002144.

6. Whooley MA. Depression and cardiovascular disease: healing thebroken-hearted. JAMA [periódico na Internet]. 2006 [acesso 6 jun 2012]; 295:2874-81. Disponível em: http://dgim.ucsf.edu/heartandsoulstudy/pdf/ Whooley_JAMA062806.pdf.

7. World Federation for Mental Health. Mental Health and Chronic Physical illnesses: The need for continued and integrated care. World Mental Health Day. [periódico na Internet]. 2010 [acesso 29 maio 2012]. Disponível em: http://www.wfmh.org/2010DOCS/WMHDAY2010.pdf 8. Souza JA, Fontana JL, Pinto MA. Depressão: uma doença, várias apresentações. In: Horimoto FC, Ayache DCG, Souza JA. Depressão. Diagnóstico e tratamento clínico. São Paulo: Editora Roca; 2005. p. 1-12.

9. WHO. World Heart Federation; World Stroke Organization. Atlas on cardiovascular disease prevention and control. Geneva: WHO; 2011. 164 p.

10. Teich V; Araújo DV. Estimativa de custo da síndrome coronariana aguda no Brasil. Rev Bras Cardiol. [periódico na Internet]. 2011 [acesso 6 jun 2012]; 24(2):8594. Disponível em http://sociedades.cardiol.br/socerj/ revista/2011_02/a_2011_v24_n02_02estimativa.pdf 
11. Mattos MA, Lougon M, Tura BR, Pereira BB. Depressão e Síndrome Isquêmica Coronariana Aguda. Rev SOCERJ. [periódico na Internet]. 2005 [acesso 6 jun 2012]; 18(4):288-94. Disponível em: http://sociedades.cardiol. br/socerj/revista/2005_04/a2005_v18_n04_art02.pdf. 12. Fauerbach JA, Bush DE, Mccann UD, Thombs BD, Fogel J, Ziegelstein RC. Depression following acute myocardial infarction: a prospective relationship with ongoing health and function. Psychosomatics. [periódico na Internet]. 2005 [acesso 6 jun 2012]; 46(4):355-61. Disponível em: http://www.sciencedirect.com/science?_ ob $=$ MiamiImageURL\&_cid $=280410 \&$ user $=5674931 \&$ _ $\mathrm{pii}=S 0033318205700748 \& \_c h e c k=y \&$ origin $=$ article\&_ zone=toolbar\&_coverDate $=31$-Aug-2005\&view $=$ c\&ori ginContentFamily $=$ serial $\&$ wchp $=d G L b V B A-z S k z S \& m d 5$ =59be739b020313914c3602da21032625\&pid=1-s2.0S0033318205700748-main. pdf\&sid=2b7ad301-d7aff60d-c9a4-6c9f046a9bcf.

13. Rumsfeld JS, Magid DJ, Plomondon ME, Sales AE, Grunwald GK, Every NR, et al. History of depression, angina, and quality of life after acute coronary syndromes. Am Heart J[periódico na Internet]. 2003 [acesso 6 jun 2012]; 145(3):493-9. Disponível em: http://www.sciencedirect.com/science?_ ob $=$ MiamiImageURL\&_cid $=272407 \& \_u s e r=5674931 \&$ _ $\mathrm{pii}=\mathrm{S} 0002870303000103 \& \_$check $=y \&$ \&origin $=$ article\&_ zone=toolbar\&_coverDate $=31-$ Mar-2003\&view $=$ c\&ori ginContentFamily = serial\&wchp $=d G L z V B A-z S k z k \& m d 5$ $=f 5022 \mathrm{e} 4 \mathrm{f} 8 \mathrm{e} 42948 \mathrm{fb} 175695420 \mathrm{c} 9 \mathrm{e} 48 \mathrm{~d} \& \mathrm{pid}=1-\mathrm{s} 2.0-$ s0002870303000103-main.pdf\&sid=dcf5fe64-8cc17364-abd0-a4550186374c.

14. Beck AT, Ward CH, Mendelson M, Mock J, Erbaugh J. An inventory for measuring depression. Arch Gen Psychiatry. 1961; 4:561-71.

15. Gorestein C, Andrade L. Inventário de Depressão de Beck: propriedades psicométricas da versão em português. Rev Psiquiatr Clín. 1998;25(5):245-50.

16. Kendall PC, Hollon SD, Beck AT, Hammen CI, Ingram RE. Issues and recommendations regarding use of the Beck Depression Inventory. Cognit Ther Res. 1987;11:89-99.

17. Fayers PM, Machin D. Quality of life. Assessment, analyses and interpretation. 2th.ed. Chichester, England: John Wiley; 2007. 342 p.

18. Bergman E, Malm D, Karlsson JE, Bertero C. Longitudinal study of patients after myocardial infarction: Sense of coherence, quality of life, and sympoms. Heart Lung [periódico na Internet]. 2009 [acesso 6 jun 2012]; 38(2):129-40. Disponível em: http://www.sciencedirect.com/science?_ $\mathrm{ob}=$ MiamiImageURL\&_cid $=272318 \&$ _user $=5674931 \&$ $\mathrm{pii}=\mathrm{S} 0147956308001027 \&$ _check $=y \&$ \&origin $=$ article\&_ zone=toolbar\&_coverDate $=30-A p r-2009 \&$ view $=$ c\&orig inContentFamily =serial\&wchp=dGLbVIS-zSkWA\&md5 =339917705bde5f1e4cb1e7a04c243494\&pid=1-s2.0S0147956308001027-main.pdf\&sid=c16fa831-df6d9c05-9188-88938c00f1af.

19. Lunelli RP, Portal VL, Esmério FG, Moraes MA, Souza EN. Adesão medicamentosa e não medicamentosa de pacientes com doença arterial coronariana. Acta Paul Enferm. [periódico na Internet]. 2009 [acesso 6 jun 2012]; 22(4):367-73. Disponível em: http://www. scielo.br/pdf/ape/v22n4/a03v22n4.pdf.

20. Norris CM, Hegadoren K, Pilote L. Depression symptoms have a greater impact on the 1-year health-related quality of life outcomes of women post-myocardial infarction compared to men. Eur J Cardiovasc Nurs. 2007;6(2):92-8. 21. Zuidersma M, Ormel J, Conradi HJ, Jonge P. An increase in depressive symptoms after myocardial infarction predicts new cardiac events irrespective of depressive symptoms before myocardial infarction. Psychol Med. [periódico na Internet]. 2011 [acesso 19 jun 2012]; 42:683-93. Disponível em: http://journals. cambridge.org/download.php?file=\%2FPSM\%2FPSM42 _04\%2FS0033291711001784a.pdf\&code $=9284 d 2995 d$ a3314f454f2789ffa4ab4d

22. Lima FET, Araújo TL, Serafim ECG, Custódio IL. Protocolo de consultas de enfermagem ao paciente após a revascularização do miocárdio: influência na ansiedade e depressão. Rev. Latino-Am. Enfermagem. [periódico na Internet]. mai-jun 2010 [acesso 6 jun 2012];18(3): 34-41. Disponível em: http://www.scielo.br/pdf/rlae/ v18n3/pt_06.pdf.

23. Lee GA. Determinants of quality of life five years after coronaryarterybypass graftsurgery. HeartLung [periódico na Internet]. 2009 [acesso 6 jun 2012]; 38(2):91-9. Disponível em: http://www.sciencedirect.com/science? $\mathrm{ob}=$ MiamiImageURL\&_cid $=272318 \&$ _user $=5674931 \&$ _ $\mathrm{pii}=\mathrm{S} 0147956308000605 \& \_c h e c k=y \&$ \&origin $=$ article\&_ zone $=$ toolbar\&_coverDate $=30-A p r-2009 \&$ view $=$ c\&or iginContentFamily $=$ serial $\& w c h p=d G L b V I k-s k z S \& m d 5$ =1f38da0329c73cdae2970d04a711903f\&pid=1-s2.0S0147956308000605-main.pdf\&sid $=2939 \mathrm{c} 9 \mathrm{e} 5-5 \mathrm{cdb}-$ c0b0-6410-c07e501e0199\&sid=f1e8a922-12e5-3dfca516-08d19530b92a.

24. Doyle F, McGee HM, Conroy RM, Delaney M. What predicts depression in cardiac patients: sociodemographic factors, disease severity or theoretical vulnerabilities. Psychol Health. [periódico na Internet]. 2011 [acesso 6 jun 2012]; 26(5):619-34. 
25. Zimmermann-Viehoff $F$, Orth-Gomer $K$, Wang HX, Deter HC, Merswolken M, Ghadiyalia Z et al. Depressive Symptoms and Heart Rate Variability in Younger Women after an Acute Coronary Event. Eur J Cardiovasc Prev Rehabil. [periódico na Internet]. 2010 [acesso 5 jul 2012]; 17(5):509-13. Disponível em: http://www. ncbi.nlm.nih.gov/pmc/articles/PMC2946964/pdf/ nihms190021.pdf 